\title{
Über die Wirkung einiger Medikamente auf das ausgeschnittene mit kolloidaler Nährflüssigkeit ernährte Froschherz.
}

\author{
Von \\ Minoru Terui. \\ (照 井 望) \\ (Aus der Medizinischen Klinik von Prof. Dr. T. Kato, \\ Tohoku Reichsuniversität zu Sendai.)
}

Bei pharmakologischen Untersuchungen am Froschherzen sind bisher vorwiegend herausgeschnittene Herzen zur Anwendung gekommen, und dabei als die Nährfüssigkeit ist meistens die RingerLösung verwendet worden. In Wirklichkeit aber ist das Herz nicht etwa durch Krystalloidlösung, wie die Ringer-Lösung, sondern durch eine kolloidale Flüssigkeit, das eiweisshaltige Blut ernährt. Es ist auch zu bemerken, dass beim Froschherzen, weil gerade diesem die Coronargefässe fehlen, die Ringer-Lösung bzw. das Blut und auch zu diesen zugesetzte Pharmaca durch das Endocard hinduch direkt in das Herzmuskelinnere hineindringen. Demgemäss wäre es wohl selbstverständlich, dass je nachdem die anzuwendende Nährflüssigkeit eine krystalloide Lösung, wie die Ringer-Lösung, oder eine kolloidale Lösung, wie das Blut darstellt, auch darin enthaltene Pharmaca in der Geschwindigkeit und dem Grad, mit denen sie in den Herzmuskel eindringen, sich verschieden verhalten können, so dass in den Wirkungen der betreffenden Mittel irgendwelche Abweichungen vorkommen.

Von diesem Gesichtspunkt aus sei auf die Arbeiten der Vorgänger eingegangen. Heffte $\mathbf{r}^{1)}$ hat die Beobachtung gemacht, dass bei der Durchströmung mit der Nährflüssigkeit mit Serumzusatz das isolierte Froschherz raseh ermüdet war. Entgegen dieser Beobachtung hat Martius ${ }^{2)}$ hervorgehoben, dass die Durchströmungsflüssigkeit, die das Serumalbumin enthält, imstande sei, das isolierte Froschherz gut arbeiten zu lassen. Albanes $\mathrm{e}^{3\rangle}$ hat bei Anwendung der Durehströmungsflüssigkeit mit Zusatz von $2 \%$ igem Gummi arab. beobachtet, dass das isolierte Froschherz unter dem Sauerstoffangebot in ähnlicher

1) Heffter, Arch. f. exp. Pahthol, w. Pharmacol., 1892, 29, 41.

2) Martius, Arch. f. Physiol., 1882, 542.

3) Albanese, Arch. f. exp. Pathol. u. Pharmacol., 1893, 32, 297. 
Weise, wie in situ, seine Aktion lange Zeit hindurch lebhaft fortsetzte; auch zu demselben Ergebnis kam er bei Anwendung der Durchspülflüssigkeit mit Zusatz vom normalen defibrinierten Ochsenblut. Indessen hat Lock $\mathrm{e}^{4)} \mathrm{den}$ Einwand dagegen erhoben, dass eine derartige Wirkung der Gummilösung auf die Wirkungen des darin enthaltenen Kalzium- und Kaliumsalzes bezogen werden müsse.

Ishigami ${ }^{5)}$ hat am isolierten Froschherzen nachgewiesen, dass, als er durch Durchströmung des Froschherzens mit einer Nährlösung, die das Kongorot, einen kolloidalen Farbstoff, in einer Konzentration von 0,005 \% enthielt, das Herz zum Schlagen brachte, dasselbe leicht ermüdbar wurde; des weiteren beobachtete er, dass, wenn er unter der Durchströmung mit ein und derselben Nährlösung Curare zu derselben hinzusetzte, die herzlähmende Wirkung der Curare abgeschwächt wurde, während er in bezug auf die Wirkungen des Adrenalins und Strophanthins auf das Herz jedwede Veränderung vermisste. Nakashima ${ }^{6)}$ konnte nachweisen, dass beim schlagenden, mit der RingerLösung durchströmten Froschherzen dann, wenn dieselbe mit der Gummilösung in einem Mengenverhältnis von $0,1 \%$ versetzt wurden, positiv inotrope Wirkungen eintraten.

Wie dem auch sei, gehen diesbezügliche Untersuchungen alle auf die frühere Zeit zurück und liegen recht spärlich vor. Ishiga mis ist der einzige gewesen, der die Beobachtung über pharmakologische Wirkungen bei Anwendung kolloidaler Nährflüssigkeit angestellt hat.

Bei Anwendung kolloidaler Nährlösung aber muss besondere Rücksicht auf das osmotische Verhalten der betreffenden Kolloide genommen werden. Denn jenach dem Verhalten des kolloid-osmotischen Drucks (k.o.D.) kann die Aufnahmefähigkeit der Pharmaca in die Herzmuskulatur verschieden stark beeinflusst werden. Gleichwohl ist von keinem von oben genannten Autoren dieser wichtige Faktor gebührend beachtet worden. Bei Durchströmung des isolierten Froschherzens kommt es nämlich in erster Linie darauf an, die Nährflüssigkeit womöglich der natürlichen angenähert entsprechen zu lassen, d. h. den k.o.D. der Nährlösung demselben des Froschblutes annähernd gleichzustellen.

Hierbei muss allerdings die Frage aufgeworfen werden, ob und inwieweit die Herzfunktion sich bei der Durchströmung des isolierten Froschherzens mit der Ringer-Lösung, welche durch Zusatz von $6 \%$ iger Gummilösung oder von dem Serum des gesunden Kaninchens annähernd den gleichgrossen k.o.D. wie das Froschserum besitzt, verschieden verhält und des weiteren ob irgendwelche Beeinflussung bei Durchströmung mit oben erwähntem Ringer-Gemisch die applizierten

4) L o c ke, Journ. Physiol., 1895, 18, 332.

5) Ishigami, Nippon Yakubutsugaku Zasshi, 1927-28, 6, 283.

6) Naka shima, Mitt. ans d. Grenzgebiete d. Med. v. Chirurg, 1928-30, 41, 273. 
Pharmaca in bezug auf ihre Einwirkungen auf das betreffende Herz erleiden; um eine Entscheidung darüber zu treffen, sind vorliegende Versuche angestellt worden.

Versuchsmethode: Als Versuchsmaterial wurden männliche Rana nigromaculata von $20-25 \mathrm{~g}$ Körpergewicht benützt. Von 2 Tagen vor dem Versuch an wurden alle Tiere im Laboratorium bei der Zimmertemperatur von $21^{\circ} \mathrm{C}$ gehalten, damit gleiche Bedingungen geschaffen werden konnten. Nach Isolierung jedes einzelnen Herzens nach der Methode von Straub und Yagi liess man es in RingerLösung* weiter schlagen. Als kolloidale Nähıflüssigkeit wurden folgende zweierlei Nährlösungen verwendet.

1. Nährflüssigkeit, welche durch Vermischen einer $6 \%$ igen, mit Natriumkarbonat neutralisiertem Gummilösung mit gleichen Mengen von Ringer-Lösung hergestellt wurde (im folgenden kurz G. R.).

2. Nährflüssigkeit, welche durch Vermischen des Blutserums des gesunden Kaninchens mit gleichen Mengen von Ringer-Lösung zubereitet wurde (im folgenden kurz S.R.). K.o.D. der ersten und zweiten Nährflüssigkeit betrug gleichfalls $70 \sim 100 \mathrm{~mm} \mathrm{H}_{2} \mathrm{O}$, während der k.o.D. des Froschserums sich nach meinen Messungen auf durchschnittlich $75 \mathrm{~mm} \mathrm{H}_{2} \mathrm{O}$ (entsprechend $3,46 \%$ Eiweiss) beläuft. Als Pharmaca, welche man auf das Herz einwirken liess, fanden die Anwendung Adrenalin, Chlorkalzium, Atropinsulfat, Chloralhydrat und Digitoxin. Oben angeführte Pharmaca wurden nachdem das isolierte Herz mehrere Minuten lang in kolloidaler Nährlösung geschlagen hat, einzeln zu derselben zugesetzt.

Versuchsergebnisse.

1. Gummi-Ringer als Nührflüssigkeit (Fig. 1,a).

Ein Straub-Yagi'sches Froschherzpräparat wird, sobald die Nährflüssigkeit von Ringer-Lösung auf G.R. umgeschaltet wird, an der Systole in äusserst geringem Masse gesteigert, hingegen an der Diastole sehr rasch und deutlich herabgesetzt, was aber nach einiger Zeit wieder auf den früheren Zustand zurückkommt.

2. Serum-Ringer als Nährflüssigkeit (Fig. 1, b).

Bei dem isolierten, ebenfalls in Ringer-Lösung schlagenden Herzen tritt unmittelbar nach der Umschaltung der Nährflüssigkeit auf S. R. eine Verstärkung der Systole ein; nach dem Verhalten des ganzen

*) Ringer-Lösung von der Zusammensetzung: $0,3 \mathrm{~g} \mathrm{CaCl}_{2}, 0,45 \mathrm{~g} \mathrm{KCl}, 9,75 \mathrm{~g} \mathrm{NaCl}$, $0,3 \mathrm{~g} \mathrm{NaHCO}, 1500 \mathrm{ccm} \mathrm{Aq.} \mathrm{dest.}$ 
Herżens beurteilt, wird die mehr oder weniger Vergrösserung der Amplitude angetroffen, welcher Zustand weiter fortdauert.
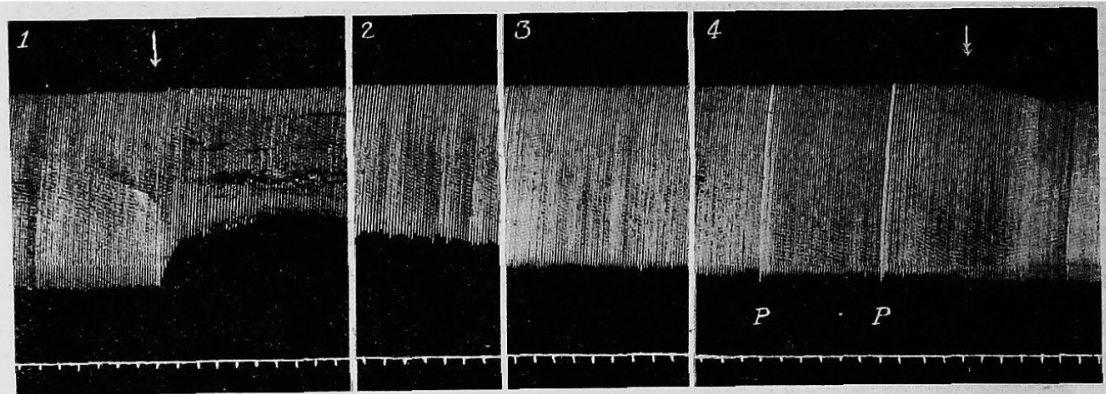

Fig. 1. a) Aktion des isolierten mit Gummi-Ringer ernährten Froschherzens.

$\downarrow$ : Umschaltung auf Gummi-Ringer.

¿: Umschaltung auf Ringer.

P: eine Pause von 3 Minuten.

Zwischen 1 und 2 eine Pause von 2 Minuten, zwischen 2 und 3 sowie zwischen 3 und 4 je eine solche von 1 Min. Zeitmarkierung in 12 Sekunden.
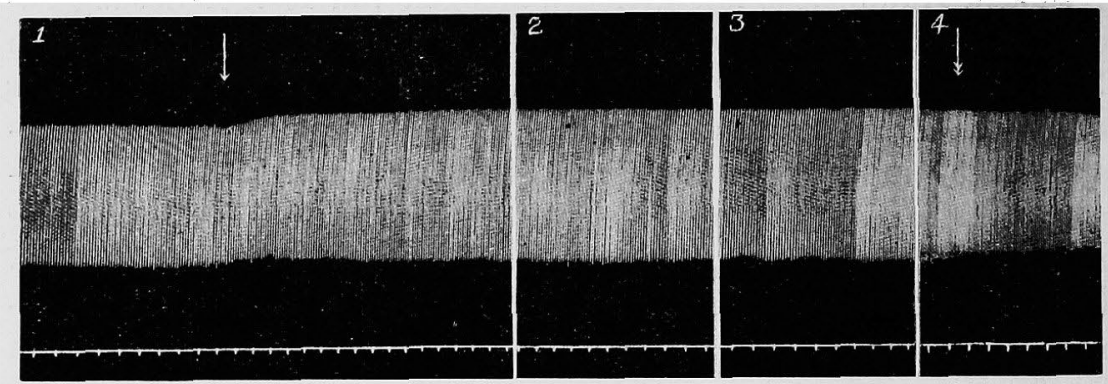

Fig. 1. b) Aktion des isolierten mit Serum-Ringer ernährten Froschherzens.

$\downarrow$ : Umschaltung auf Serum-Ringer.

$\downarrow$ : Umschaltung auf Ringer.

Zwischen 1 und 2 eine Pause von 3 Minuten, zwischen 2 und 3 sowie zwischen 3 und 4 je eine solche von 3 Minuten. Zeitmarkierung in 12 Sekunden.

3. Adrenalinwirkung.

Indem man das Straub-Yagi'sche Herz mit $1 \mathrm{ccm}$ Nährflüssigkeit schlagen lässt, setzt man zu derselben $0,1 \mathrm{ccm} 0,0001 \%$ iger Lösung von Adrenalin (Adrenalin chloride, Sankyo) hinzu.

Wenn die Nährlösung die Ringer-Lösung ist, tritt sofort nach Zusatz von Adrenalin eine erhebliche Verstärkung der Systole ein, wobei auch die Diastole sich ein wenig verstärkt. Nach dem Verhalten des ganzen Herzens beurteilt, stellt sich eine merkliche Vergrösserung der Amplitude ein. (Fig. 2, a).

Wenn die Nährflüssigkeit G.R. oder S.R. ist, wird eine derartige Adrenalinwirkung fast völlig vermisst (Fig. 2, b u. c). 


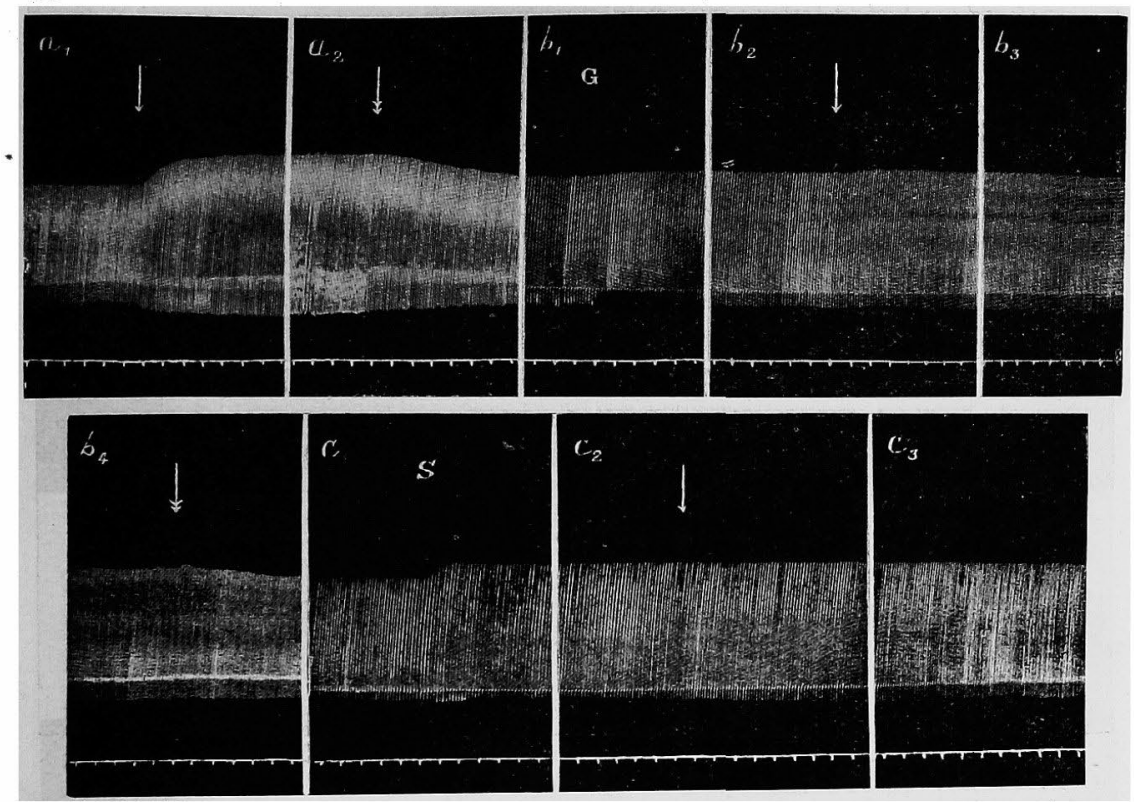

Fig. 2. Adrenalinwirkung auf isolierte mit kolloidaler Nährflüssigkeit ernährte Froschherz.

Bei $\downarrow$ Adrenalin zugesetzt. Bei $\downarrow$ mit Ringer ausgewaschen.

a : Ernährung mit Ringer. b: Ernährung mit Gummi-Ringer

G : Umschaltung auf Gummi-Ringer. c: Ernährung mit SerumRinger. c: Ernährung mit Serum-Ringer S: Umschaltung auf Serum-Ringer. Zeitmarkierung in 12 Sekunden.

4. Atropinwirkung.

Beim Zusatz von 0,1 ccm 0,1 \% iger Lösung von Atropinum sulfuricum zu $1 \mathrm{ccm}$ Nährflüssigkeit: Bei Anwendung von Ringer-Lösung als Nährflüssigkeit wird nach Zusatz des Mittels die Systole nach und nach unterdrückt (Fig. 3, a). Bei vorausgegangener Durchströmung mit G.R. oder S.R. tritt aber diese die Systole unterdrückende Atropinwirkung kaum in Erscheinung (Fig. 3, b u. c).

5. Chlorkalziumwirkung.

Beim Zusatz von $0,1 \mathrm{ccm} 0,5 \%$ iger Chlorkalziumlösung zu $1 \mathrm{ccm}$ Nährflüssigkeit, mit welcher das isolierte Herz schlägt: Wenn als die Nährflüssigkeit die Ringer-Lösung dient, treten im direkten Anschluss an den Zusatz von dem Mittel eine ganz geringfügige Verstärkung der Systole und eine deutliche Abschwächung der Diastole auf, welch letztere aber nacher allmählich auf den früheren Zustand zurückkommt (Fig. 4, a). 


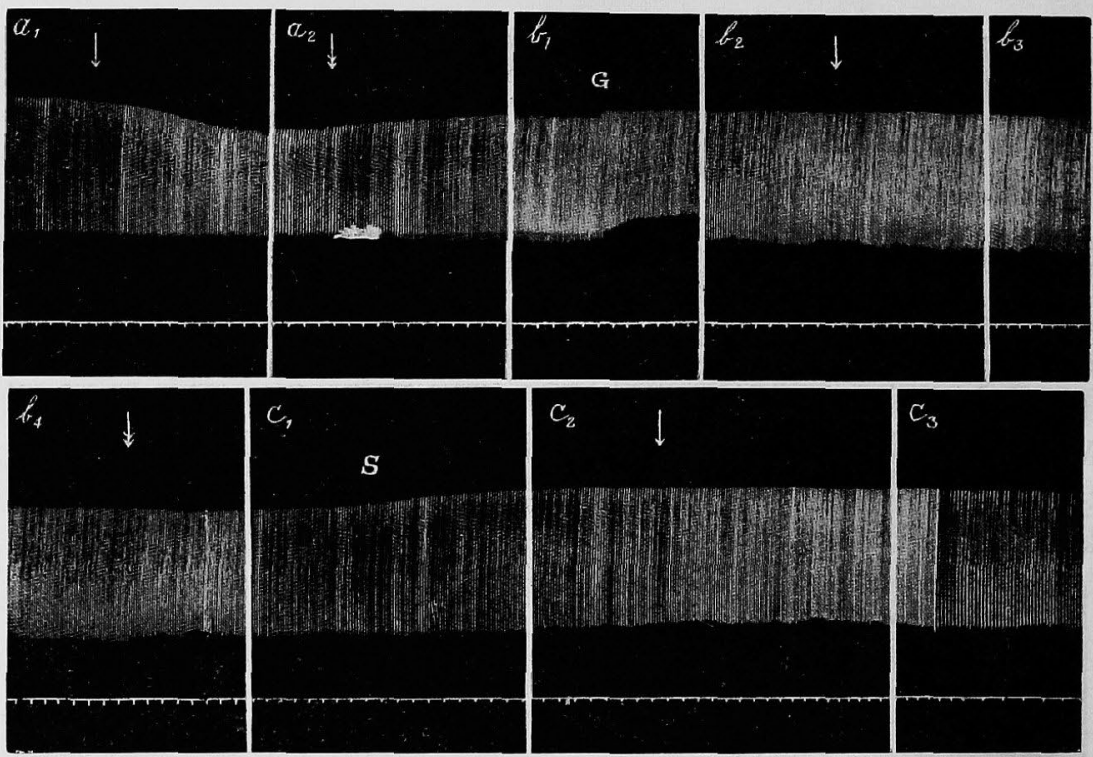

Fig. 3. Atropinwirkung auf isolierte, mit kolloidaler Nährflüssigkeit, ernährte Froschherz.

Bei $\downarrow$ Atropin zugesetzt. Bei $\downarrow$ mit Ringer ausgewaschen.

a: Ernährung mit Ringer. b: Ernährung mit Gummi-Ringer. c : Ernährung mit Serum-Ringer. G : Umschaltung auf GummiRinger. S: Umschaltung auf Serum-Ringer. Zeitmarkierung in 12 Sekunden.

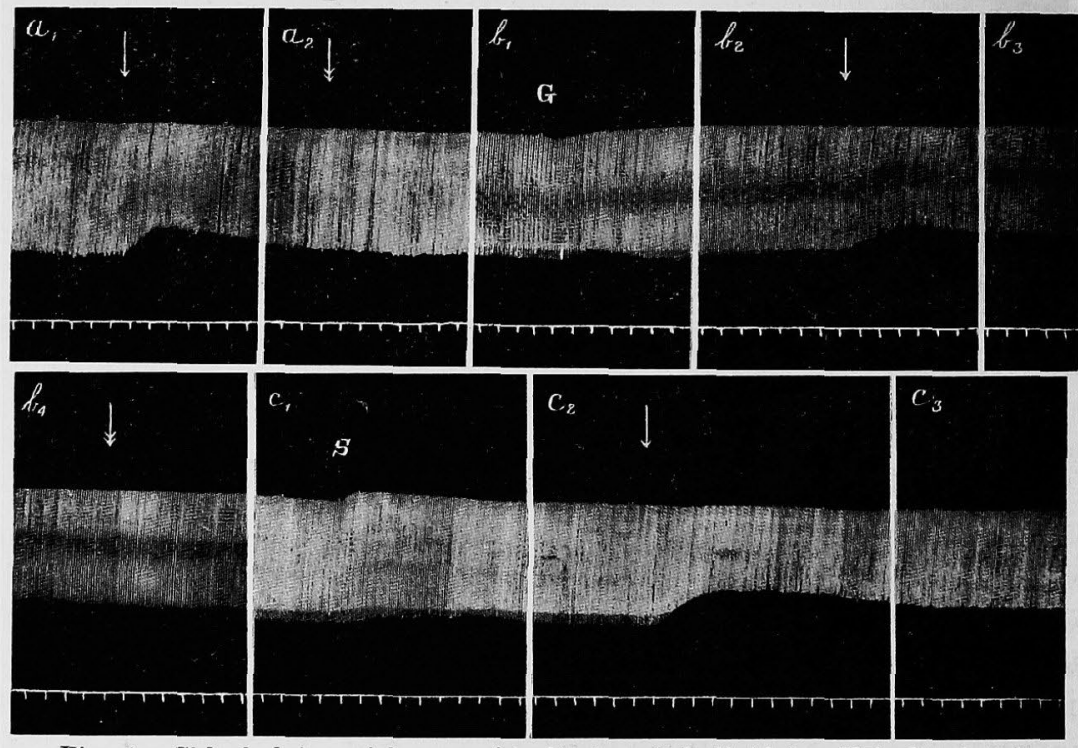

Fig. 4. Chlorkalziumwirkung auf isolierte, mit kolloidaler Nährflüssigkeit ernährte Froschherz.

Bei $\downarrow$ Chlorkalzium zugesetzt. Bei $\downarrow$ mit Ringer ausgewaschen.

a : Ernährung mit Ringer. b: Ernährung mit Gummi-Ringer.

c: Ernährung mit Serum-Ringer. G : Umschaltung auf Gummi- 
Auch bei der Durchströmung mit G. R. oder S.R. zeigt die Chlorkalziumwirkung auf das Herz keinen merklichen Unterschied von derselben bei Anwendung von Ringer-Lösung (Fig. 4, b u. c).

6. Chloralhydratwirkung.

Beim Zusatz von $0,1 \mathrm{ccm} 5 \%$ iger Chloralhydratlösung zu $1 \mathrm{ccm}$ Nährflüssigkeit: Das Chloralhydrat entfaltet ganz denselben Effekt, gleichviel, ob die Nährflüssigkeit Ringer-Lösung oder G.R. oder S.R. ist. Dreien Nährflüssigkeiten ist nämlich die Wirkung des Chloralhydrates gemeinsam, die sich darin äussert, dass sofort nach Zusatz des Mittels der Muskeltonus gesteigert, die Diastole beträchtlich beeinträchtigt ist, wobei die Amplitude des Herzens sich bedeutend verkleinert (Fig. 5, a b u.c).
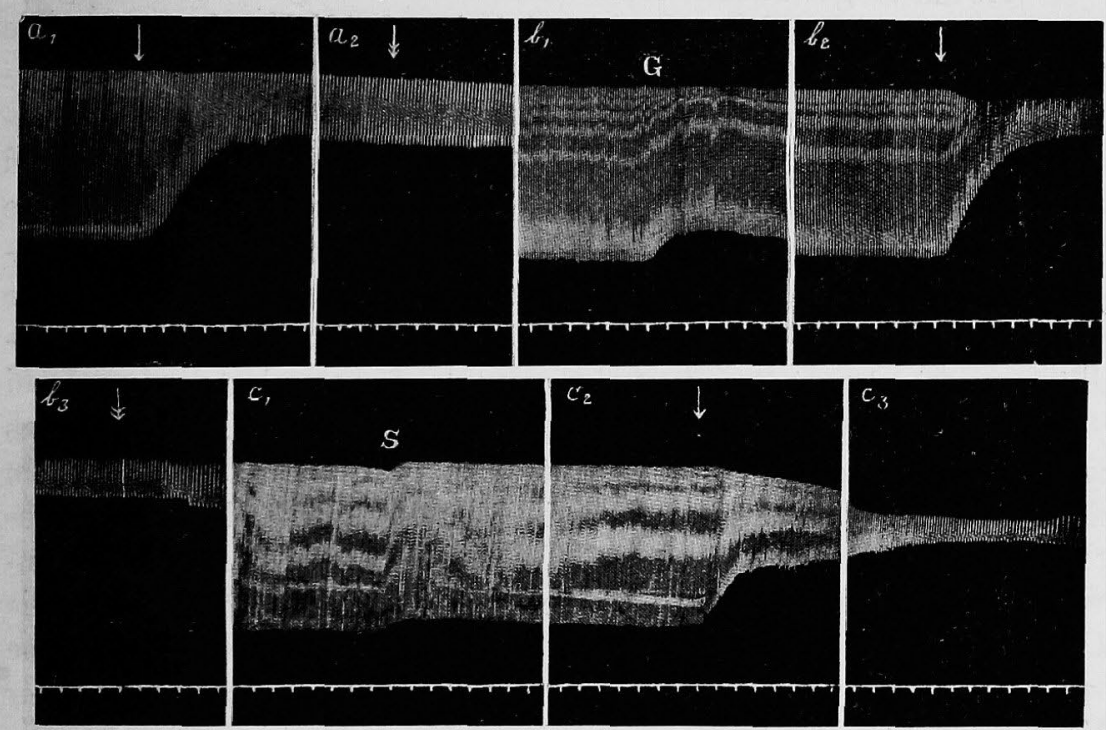

Fig. 5. Chloralhydratwirkung auf isolierte mit kolloidaler Nührflüssigkeit ernährte Froschherz.

Bei $\downarrow$ Chloral zugesetzt. Bei $\downarrow$ mit Ringer ausgewaschen.

a : Ernährung mit Ringer. b: Ernährung mit Gummi-Ringer. c : Ernährung mit Serum-Ringer. G : Umschaltung auf GummiRinger. S: Umschaltung auf Serum-Ringer. Zeitmarkierung in 12 Sekunden.

7. Digitoxinwirkung.

Indem man das isolierte Herz mit $1 \mathrm{ccm}$ Nährflüssigkeit schlagen lässt und darauf zu derselben 0,1 ccm 0,005 \%iger Digitoxinlösung hinzusetzt, wird die Zeitdauer, in welcher der Stillstand des Herzes eintritt, beobachtet. In beistehender Tabelle ist die Zeitdauer bis zum Eintritt des Stillstandes aufgezeichnet. 
Tabelle

\begin{tabular}{l|c|c}
\hline Nährflüssigkeit & Versuch & Zeitdauer bis zum Stillstand \\
\hline \multirow{2}{*}{ Ringer-Lösung } & 1 & $16^{\prime} 48^{\prime \prime}$ \\
& 3 & $17^{\prime} 48^{\prime \prime}$ \\
$16^{\prime} 12^{\prime \prime}$ \\
\hline \multirow{3}{*}{ Gummi-Ringer } & 3 & $18^{\prime}$ \\
& 2 & $19^{\prime} 12^{\prime \prime}$ \\
& 3 & $19^{\prime} 48^{\prime \prime}$ \\
\hline \multirow{3}{*}{ Serum-Ringer } & 1 & $65^{\prime} 24^{\prime \prime}$ \\
& 2 & $50^{\prime}$ \\
& 3 & $68^{\prime} 36^{\prime \prime}$
\end{tabular}

Wie aus obiger Tabelle ersichtlich, wird die Digitoxinwirkung bei Anwendung von S.R. als Nährfiüssigkeit erheblich gehemmt: Die Herzschläge vollziehen sich auch bei Ernährung des isolierten Froschherzens mit Gummi-Ringer in etwas stärkerem Masse als bei Ernährung mit einfacher Ringer-Lösung. Es fällt uns jedenfalls vorderhand schwer, eine Entscheidung darüber zu treffen, ob die eben angeführte Verstärkung der Herzschläge in analoger Weise, wie bei der Beobachtung Lockes ${ }^{4)}$ bei Anwendung der Gummilösung, lediglich auf die Wirkung der im Kolloide enthaltenen chemischen Substanzen zurückzuführen sei oder nicht. In Anbetracht des Umstandes, dass auch bei Anwendung kolloidaler Lösungen, welche annähernd gleichhohen k.o.D. zueinander besitzen, Resultate verschieden ausfallen, indem nämlich bei Anwendung von S.R. die Verstärkung der Herzaktion intensiver als bei Anwendung von G.R. erfolgt, und ferner dass bei Anwendung von G.R. die Diastole erheblicher gehemmt wird, dürfte die Ursache für derartige Wirkung von kolloidalen Nährlösungen, welche von derselben der Ringer-Lösung verschieden ist, nicht lediglich in der Verschiedenheit der osmotischen Wirkung zu erblicken sein.

Was den Effekt verschiedener Pharmaca auf das Froschherz, welches mit einer Nährflüssigkeit, deren k.o.D. demselben des Froschserums annähernd gleichkommt, ernährt wird, anbelangt, zeigen Chloralhydrat und Chlorkalzium gemeinschaftlich keine Wirkungsunterschiede, während die Wirkungen von Adrenalin und Atropin deutlich unterdrückt werden. Auch die Digitoxinwirkung wird bei der Ernährung des Herzens mit S.R. erheblich gehemmt.

Über die Beeinflussung der Wirkungen der Pharmaca in kolloidaler Nährflüssigkeit, mit welcher das isolierte Herz anstatt der RingerLösung ernährt wird, kommen im allgemeinen folgende 2 Möglich- 
keiten in Betracht: (1) Unter dem Einfluss der kolloidalen Substanz stellt sich irgendwelche Umstimmung in der Herzmuskulatur selbst ein, welche ihrerseits Veränderungen im Vermögen des betreffenden Pharmacums, in das Muskelinnere einzudringen, hervorruft, oder (2) durch die Bindung der Pharmaca an das Kolloid selbst wird die Fähigkeit derselben zum Eindringen in das Herzmuskelinnere gehemmt. Die Frage, welches von 2 eben angeführten Momenten überwiegt, ist einstweilen nicht zu beantworten, immerhin steht aber soviel fest, dass nur durch Zusatz von Gummi oder Serum zur Ringerlösung allein die Kontraktilität des Herzmuskels in geringem Masse und zudem transitorisch beeinflusst werden kann. Der Umstand, dass Pharmaca in den Nährlösungen des Herzens je nach ihren Arten in ihren Wirkungen elektiv kaum oder deutlich behindert werden, dürfte wahrscheinlich in der Hauptsache davon abhängig sein, ob betreffende Pharmaca je nach ihrer chemischen Struktur und ihren physiko-chemischen Eigenschaften vom Kolloid leicht oder schwer gebunden werden können. Um einen Beispiel dafür anzuführen, werden die Wirkungen von Chlorkalzium und Chloralhydrat weniger als die des Atropins und Adrenalins beeinflusst; der Grund hierfür ist wohl darin gelegen, dass die chemische Struktur der erstgenannten Pharmaca relativ einfach gestaltet ist. Während die Wirkung des Digitoxins auf das Herz in S.R. beträchtlich gehemmt wird, erfährt sie in G.R. fast keine Veränderung. Hieraus ist sicherlich zu schliessen, dass diese zweierlei Kolloide voneinander verschieden starke Adsorptionsfähigkeit gegenüber dem Digitoxin aufweisen. Der oben angeführte Befund steht im Einklang mit dem Ergebnis in Versuchen von Taka se ${ }^{7}$ über die Adsorption des Serums an das Digitoxin.

\section{Schluss.}

Um darüber ins klare zu kommen, wie verschieden das nach $\mathrm{St}$ raub und Yagi herausgeschnittene, mit kolloidaler Nährflüssigkeit ernährte Froschherz sich gegenüber dem mit gewöhnlicher RingerLösung ernährten Herzen verhält und weiterhin welches unterschiedliche Verhalten das isolierte Herz gegenüber den zu der Nährlösung hinzugesetzten Mitteln, je nachdem wenn es mit Ringer-Lösung oder mit kolloidaler Nährflüssigkeit ernährt wird, zeigt, sind vorliegende Versuche angestellt worden.

1. Wenn das Froschherz mit Ringer-Lösung mitZusatz von Gum-

7) Takase, Wird bald in dieser Zeitschrift publiziert. 
mi arabicum oder Kaninchenserum, welch beide gleich hohen kolloidosmotischen Druck wie das Froschserum besitzen, ernährt wird, kommt es zu ein wenig stärkerer Steigerung der Herzaktion als bei Ernährung mit einfacher Ringer-Lösung.

2. Bei Durchströmung mit kolloidalen Nährlösungen werden die Wirkungen des Adrenalins und Atropins auf das Herz gehemmt, während die Wirkungen des Chloralhydrats und Chlorkalziums unter gleichen Masse wie bei Durchströmung mit einfacher Ringer-Lösung sich entwickeln.

3. Die Wirkung des Digitoxins auf das Herz wird bei Durchströmung mit Ringer-Lösung mit Zusatz von Kaninchenserum erheblich gehemmt. 